\title{
Smoking prevalence, knowledge and attitudes among primary healthcare professionals: a study from Jordan
}

M.J. Alkhatatbeh', Q. Alefan ${ }^{7}$ and M. Alzghool ${ }^{2}$

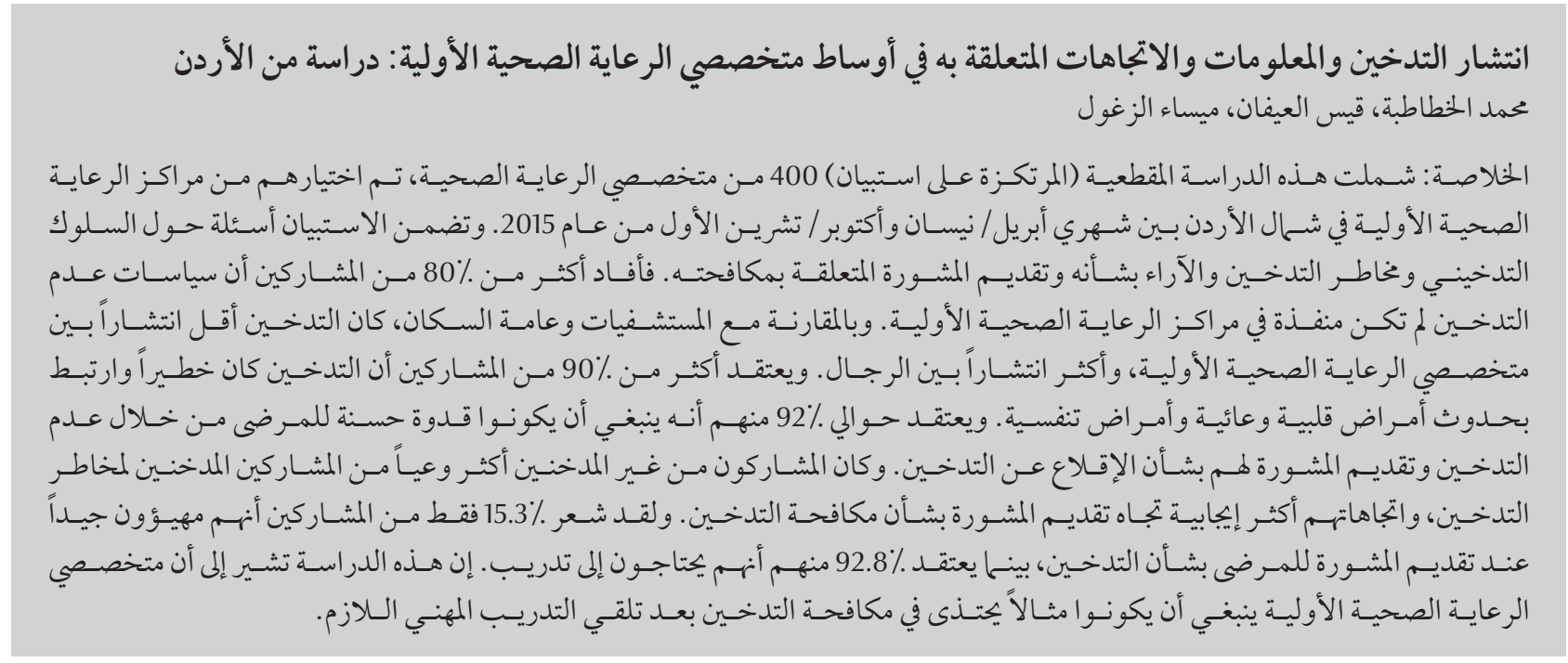

ABSTRACT This was a questionnaire-based cross-sectional study of 400 healthcare professionals recruited from primary healthcare centres in northern Jordan between April and October 2015. The questionnaire included questions about smoking behaviour, risks, opinions and providing anti-smoking counselling. More than $80 \%$ of participants reported that smoking-free policies were not enforced at primary healthcare centres. Compared to hospitals and the general population, smoking was less prevalent among primary healthcare professionals and more prevalent in men. More than $90 \%$ of participants believed that smoking was dangerous and associated with cardiovascular and respiratory diseases. Around 92\% believed that they should set a good example to patients by not smoking and advise them about smoking cessation. Only $15.3 \%$ of participants felt well prepared when counselling patients about smoking and $92.8 \%$ believed that they needed training. This study suggests that primary healthcare professionals should act as anti-smoking role models after receiving professional training.

Prévalence, connaissances du tabagisme et comportements associés parmi les professionnels de soins de santé primaires : étude jordanienne

RÉSUMÉ La présente étude transversale reposait sur un questionnaire rempli par 400 professionnels de santé issus de centres de soins de santé primaires dans le nord de la Jordanie entre avril et octobre 2015. Le questionnaire incluait des questions portant sur les comportements tabagiques, les risques liés au tabac et les opinions à ce sujet, et sur la façon d'apporter des conseils pour prévenir le tabagisme. Plus de 80 \% des participants ont rapporté que les politiques sans tabac n'étaient pas appliquées dans les centres de soins de santé primaires. Comparé aux hôpitaux et à la population générale, le tabagisme était moins prévalent parmi les professionnels de soins de santé primaires, mais plus prévalent chez les hommes. Plus de $90 \%$ des participants étaient d'avis que fumer était dangereux et associé à des maladies cardio-vasculaires et respiratoires. Environ $92 \%$ pensaient qu'ils devaient donner l'exemple aux patients en étant non fumeurs et en leur promulguant des conseils pour arrêter de fumer. Seuls 15,3 \% des participants se sentaient suffisamment préparés pour conseiller les patients sur le tabagisme, et 92,8 \% étaient d'avis qu'ils avaient besoin d'une formation. L'étude suggère que les professionnels des soins de santé primaires devraient jouer le rôle de modèles non fumeur après avoir reçu une formation professionnelle.

'Clinical Pharmacy Department, Faculty of Pharmacy, Jordan University of Science and Technology, Irbid, Jordan (Correspondence to: M.J. Alkhatatbeh: khatatbeh@just.edu.jo). ${ }^{2}$ Forensic Medicine, Legal Medicine and Toxicology Department, Faculty of Medicine, Jordan University of Science and Technology, Irbid, Jordan.

Received: 5/05/16; accepted: 30/08/16 


\section{Introduction}

Tobacco smoking is a major avoidable risk factor for cardiovascular, respiratory and malignant diseases (1). According to the World Health Organization (WHO) report on the global tobacco epidemic in 2008, tobacco smoking killed 100 million people in the 20th century and is responsible for 5.4 million deaths each year (2). More than $80 \%$ of smokers live in low-and middle-income countries (3), therefore, the WHO report expected that $80 \%$ of future smoking-related deaths would happen in these countries (2). However, the prevalence of smoking in developing countries is expected to increase from $8 \%$ to $20 \%$ among women and to decrease from $60 \%$ to $45 \%$ among men by the year 2025 (4). Exposure to passive smoking is also prevalent in developing countries $(5,6)$ and this may further increase the risk of smoking-induced diseases among non-smokers.

In Jordan, tobacco smoking is popular among the general population. A recent study of $>3000$ Jordanian adults reported that the prevalence of tobacco smoking was $54.9 \%$ in men and $8.3 \%$ in women (7). Among the smokers, 93\% used cigarette smoking and 8.6\% used waterpipe smoking. Another study showed that $82.4 \%$ and $32.8 \%$ of women reported exposure to passive cigarette and waterpipe smoking, respectively, in their houses and public places (8). Unfortunately, smoking in public places and even near family members in houses is not well controlled in Jordan. This is not because of a lack of smoking-free policies but is because policies are not properly enforced (9).

One approach to reduce the risk of smoking is to encourage the participation of healthcare professionals in campaigns against tobacco smoking (10). Local primary healthcare centres are good places for such a purpose as they receive many patients who usually come back several times for follow-up or further treatment. So, healthcare professionals at these centres may act as role models for their patients to advise them positively about smoking cessation (11). Conversely, healthcare professionals who are smokers represent an important challenge for anti-smoking campaigns as they may have negative attitudes that prevent them from providing anti-smoking advice (12).

The prevalence of smoking among physicians and nurses is considered high in low- and middle-income countries $(13,14)$. In Jordan, a high prevalence of smoking (65\%) has been reported among healthcare workers at King Hussein Medical Center (KHMC); the principal tertiary hospital in the country (15). Another study has reported a lower prevalence of smoking (38.8\%) among Jordanian healthcare professionals working at hospitals other than KHMC (16). To the best of our knowledge, no previous research has assessed the prevalence of tobacco smoking among healthcare professionals working at primary healthcare centres in Jordan. These centres are widely distributed throughout cities, towns and small villages where healthcare professionals may act as good anti-smoking models for their patients.

Therefore, the major objectives of the current study were to determine the prevalence of cigarette smoking among healthcare professionals working at primary healthcare centres in northern Jordan, and to assess smoking practices and available interventions for smoking cessation at these centres. Additionally, this study assessed differences between smoking and non-smoking healthcare professionals regarding their knowledge about the risk of smoking and their opinions about providing smoking cessation advice.

\section{Methods}

A questionnaire-based cross-sectional study was conducted between April and October 2015. The study procedure was approved by the Institutional Review Board at Jordan University of Science and Technology, Reference no. 20150061.

\section{Participants}

Four hundred and seventeen healthcare professionals (i.e., physicians, nurses, dentists, pharmacists and their assistants) were recruited from primary healthcare centres in northern Jordan (Irbid, Jerash, Ajlun and Mafraq). Healthcare centres were selected by systematic random sampling, and every other centre was selected from a list for each Governorate. Available healthcare professionals at selected centres were asked to fill in the questionnaire. The response rate was $\sim 96 \%$ as 10 professionals refused to participate because of work overload and 7 incomplete responses were excluded. The sample size was determined using the formula ( $n=$ $\left.(t)^{2}(p)(q) /(d)^{2}\right)(17)$. When $t=1.96(t$ value for $95 \%$ confidence interval $), P=$ 0.65 (the expected prevalence of smoking among healthcare professionals based on a study conducted at KHMC (15)), $\mathrm{q}=1-P$, and margin of error $\mathrm{d}=$ 0.05 , the estimated sample size was 350 . However, we recruited more participants to avoid missing information that resulted from incomplete responses.

\section{Questionnaire}

The questionnaire was an Arabic modified version of the Global Health Professional Survey, which was developed by the WHO in cooperation with the US Centers for Disease Control and Prevention and modified by the Department of Family Medicine at Queen's University Belfast, UK, to collect data on tobacco use and smoking cessation counselling among healthcare professionals (11). The questionnaire was translated into Arabic using the standard forward-backward translation procedure.

The first part of the questionnaire included general questions about age, 
gender, health profession, marital status, average family income, number of family members and number of smokers in the family. The second part of the questionnaire included questions about smoking behaviour (never smoked, quit smoking or currently smoking), age at which they started smoking and number of cigarettes consumed daily. Current smoking included occasional smoking and daily smoking. The third part of the questionnaire assessed knowledge about risk of smoking by asking if smoking is dangerous to health; if smoking increases risk of respiratory and cardiovascular diseases and death among neonates; if maternal smoking is harmful to the fetus; and if smoking in public places should be prohibited. The fourth part of the questionnaire assessed opinions about providing smoking cessation advice by healthcare professionals. Questions assessed if healthcare professionals should set a good example by not smoking; if healthcare professionals should ask patients about their smoking behaviour and if they should advise them to stop smoking; if providing smoking cessation advice increases patients' chances of stopping smoking; if healthcare professionals should advise patients to avoid smoking near children and pregnant women; if smokers among healthcare professionals are less likely to provide smoking cessation advice; and if healthcare professionals should receive training on providing smoking cessation advice and on smoking cessation strategies. The final part of the questionnaire assessed smoking practices at healthcare professionals' workplaces. They were asked if there was a smoking-free policy at their workplace and if the policy was enforced. There were also questions about what kind of interventions were available at the workplace to help patients stop smoking; how well prepared did they feel when they counselled patients about smoking; and if they had received any professional training on smoking cessation counselling and strategies.
To determine if the questions were clear and well understood by healthcare professionals, the questionnaire was revalidated on 10 participants who were then excluded from the study. The aim of the study was described to all participating healthcare professionals before obtaining their consent to participate in the study and fill in the questionnaire by self-administration.

\section{Statistical analysis}

Data were entered into Microsoft Excel and analysed using SPSS version 18 (Chicago, IL, USA). Descriptive data were expressed as frequency and percentage, while data for continuous variables were expressed as mean (standard deviation). $X^{2}$ and Fisher's exact tests were used to detect significant differences between smoking and nonsmoking or between male and female respondents. $P$ values were 2 -sided and considered statistically significant when they were $<0.05$.

\section{Results}

\section{General and socioeconomic characteristics}

The questionnaire was completed by $400(96 \%)$ of 407 healthcare professionals who were asked to participate in the study. The average age was 39.4 (9.5) years; the average number of family members was $5.21( \pm 1.91)$; and the average number of smokers in the family was $1.0( \pm 1.0)$. Other characteristics are listed in Table 1.

\section{Prevalence of cigarette smoking}

Cigarette smoking was reported in 102 (25.5\%) respondents. Among nonsmoking healthcare professionals $(n=298,74.5 \%), 30$ (10.1\%) had quit cigarette smoking previously. Healthcare professionals' smoking habit did not different significantly between physicians (34.3\%), dentists (27.5\%), pharmacists $(20 \%)$, nurses $(24.6 \%)$ or other healthcare professionals (26.1\%) $(P=0.53)$ (Table 2$)$. In contrast, smoking habit was significantly dependent on gender ( $47.6 \%$ in men vs $15.3 \%$ in women, $P<0.01)$. Healthcare professionals had started smoking at age 21.67 $( \pm 6.12)$ years and they consumed 22.3 $( \pm 13.62)$ cigarettes daily.

\section{Healthcare professionals' knowledge about risk of smoking}

Three hundred and ninety-three (98.2\%) respondents believed that smoking was dangerous to health ( $\mathrm{Ta}-$ ble 3). Three hundred and sixty-one (90.2\%) respondents believed that smoking (including passive smoking) was associated with increased risk of cardiovascular diseases, and 376 (94\%) that it was also associated with increased risk of respiratory diseases. Regarding maternal smoking, 322 (80.5\%) respondents believed that it was harmful to the fetus, whereas only 265 (66.2\%) believed that smoking increased the risk of neonatal death. Nevertheless, 381 (95.2\%) respondents believed that smoking should be prohibited in public places, especially hospitals and healthcare centres. Nonsmoking healthcare professionals were more aware about the risk of smoking compared to smokers $(P<0.05)$.

\section{Healthcare professionals' opinions about providing smoking cessation advice}

Three hundred and seventy-one (92.8\%) respondents believed that they should set a good example to their patients by not smoking. In addition, 328 (82\%) believed that they should ask patients about their smoking behaviour, and 368 (92\%) believed that they should advise their patients about smoking cessation. Only 245 (61.2\%) respondents believed that providing such advice would increase the possibility of patients quitting smoking, and 350 (87.5\%) believed that healthcare professionals who smoked were less likely to provide smoking cessation advice. 


\begin{tabular}{|c|c|c|c|}
\hline Variable & $\begin{array}{c}\text { Non-smokers } \\
(n=298)(\%)\end{array}$ & $\begin{array}{c}\text { Smokers } \\
(n=102)(\%)\end{array}$ & $\begin{array}{c}\text { Total } \\
(n=400)(\%)\end{array}$ \\
\hline \multicolumn{4}{|l|}{ Gender } \\
\hline Male & $66(22.1)$ & $60(58.8)$ & $126(31.5)$ \\
\hline Female & $232(77.9)$ & $42(41.2)$ & $274(68.5)$ \\
\hline \multicolumn{4}{|l|}{ Health profession } \\
\hline Physician & $23(7.7)$ & $12(11.8)$ & $35(8.8)$ \\
\hline Dentist & $37(12.4)$ & $14(13.7)$ & $51(12.8)$ \\
\hline Pharmacist & $44(14.8)$ & $11(10.8)$ & $55(13.8)$ \\
\hline Nurse & $126(42.3)$ & $41(40.2)$ & $167(41.8)$ \\
\hline Other & $68(22.8)$ & $24(23.5)$ & $92(23)$ \\
\hline \multicolumn{4}{|l|}{ Marital status } \\
\hline Single & $38(12.8)$ & $16(15.7)$ & $54(13.5)$ \\
\hline Married & $252(84.6)$ & $83(81.4)$ & 335 (83.8) \\
\hline Divorced/widowed & $8(2.7)$ & $3(2.9)$ & $11(2.8)$ \\
\hline \multicolumn{4}{|c|}{ Average family monthly income (JD) } \\
\hline$<400$ & $71(23.8)$ & $23(22.5)$ & $94(23.5)$ \\
\hline $400-700$ & $122(40.9)$ & $42(41.2)$ & $164(41)$ \\
\hline 701-1000 & $53(17.8)$ & 17 (16.7) & 70 (17.5) \\
\hline$>1000$ & $52(17.4)$ & $20(19.6)$ & $72(18)$ \\
\hline
\end{tabular}

However, 390 (97.5\%) respondents believed that they should advise their patients to avoid smoking near children and pregnant women. Three hundred and seventy-one (92.8\%) respondents believed that healthcare professionals need professional training on providing smoking cessation advice and on smoking cessation strategies. Table 4 also shows differences in opinions between smoking and non-smoking respondents. Compared to smokers, non-smokers had more positive opinions about providing smoking cessation advice.

\section{Smoking practices at primary healthcare centres and available interventions for smoking cessation}

All 400 healthcare professionals reported that primary healthcare centres had a smoking-free policy according to the law of the Ministry of Health of Jordan. However, 326 (81.5\%) reported that such policies were not enforced at their workplaces. All participants also reported that counselling was the only intervention available to help their patients stop smoking. However, only 61 (15.3\%) participants reported that they felt well prepared when they counselled patients on how to stop smoking. Only 102 (25.5\%) had ever received professional training on smoking cessation during their study, specialization or through special lectures or workshops.

\section{Discussion}

The current study showed that cigarette smoking was reported by only $25 \%$ of healthcare professionals working at primary healthcare centres in northern Jordan. This was lower than the prevalence rate of smoking (65\%) among healthcare workers at the biggest tertiary hospital in Jordan (15), and lower than the prevalence rate of smoking (38.8\%) among healthcare professionals working at other hospitals (16). This suggests that healthcare professionals at primary healthcare centres may hold a more positive attitude toward smoking habits compared to those working at hospitals. This finding also suggests that they are good candidates to act against smoking at their workplaces by enforcing smoking-free policies and advising patients about smoking cessation. This possible role may also be supported by the fact that the smoking prevalence rate reported in this study was lower than the smoking rate of the general population in Jordan (32.3\%) (7).

Smoking habits among healthcare professionals in this study was not significantly dependent on their profession, although smoking rates were higher among physicians and dentists compared to nurses and pharmacists. Smoking habit was significantly higher among men than women. These findings are consistent with other studies on healthcare professionals and the general population in Jordan $(7,15,16)$. These results were expected as the reported smoking prevalence rate in developing countries was also higher in men than women, and because smoking among women is not generally accepted culturally by the Jordanian population (18). So, these findings suggest that female 


\begin{tabular}{|c|c|c|c|c|c|c|c|c|c|}
\hline $\begin{array}{l}\text { Smoking } \\
\text { behaviour }\end{array}$ & $\begin{array}{c}\text { Physicians } \\
(n=35) \\
(\%)\end{array}$ & $\begin{array}{c}\text { Dentists } \\
(n=51) \\
(\%)\end{array}$ & $\begin{array}{c}\text { Pharmacists } \\
(n=55) \\
(\%)\end{array}$ & $\begin{array}{c}\text { Nurses } \\
(n=167) \\
(\%)\end{array}$ & $\begin{array}{c}\text { Others } \\
(n=92) \\
(\%)\end{array}$ & $P$ value $^{\mathrm{a}}$ & $\begin{array}{c}\text { Male } \\
(n=126)(\%)\end{array}$ & $\begin{array}{c}\begin{array}{c}\text { Female } \\
(\boldsymbol{n}=274) \\
(\%)\end{array}\end{array}$ & $P$ value $^{\mathrm{a}}$ \\
\hline Never smoked & $19(54.3)$ & $33(64.7)$ & $40(72.7)$ & $112(67.1)$ & $64(69.6)$ & 0.53 & $45(35.7)$ & $223(81.4)$ & $<0.01$ \\
\hline Quit smoking & $4(11.4)$ & $4(7.8)$ & $4(7.3)$ & $14(8.4)$ & $4(4.3)$ & 0.53 & $21(16.7)$ & $9(3.3)$ & $<0.01$ \\
\hline Current smoking & $12(34.3)$ & $14(27.5)$ & $11(20)$ & $41(24.6)$ & $24(26.1)$ & 0.53 & $60(47.6)$ & $42(15.3)$ & $<0.01$ \\
\hline
\end{tabular}

${ }^{a} \chi^{2}$ test.

healthcare professionals are more appropriate candidates than their male counterparts to act against smoking. This suggestion is supported by the fact that female healthcare professionals formed the majority in the present and other similar studies $(11,13,16)$.

To act as role models for their patients, healthcare professionals should have good knowledge about the risk of smoking and hold positive attitudes toward smoking cessation. Conversely, healthcare professionals who smoke may hold negative attitudes that prevent them from acting as anti-smoking role models (11). These role models should advise patients to quit smoking and to avoid smoking in public places and in houses. This is important as passive smoking is also dangerous to nonsmoking individuals (19), and because anti-smoking policies are not enforced in public places and smoking is not banned inside houses in Jordan (9). Our results show that most healthcare professionals believe that smoking is harmful to health but their beliefs about the risks of smoking are significantly dependent on their smoking status. Nonsmoking healthcare professionals

\begin{tabular}{|c|c|c|c|c|}
\hline & Response & $\begin{array}{l}\text { Non-smokers } \\
\qquad(n=298) \\
(\%)\end{array}$ & $\begin{array}{c}\text { Smokers } \\
(n=102) \\
(\%)\end{array}$ & $P$ value ${ }^{a}$ \\
\hline \multirow[t]{3}{*}{ Smoking is dangerous to health } & Agree & $298(100)$ & $95(93.1)$ & $<0.01$ \\
\hline & Undecided & 0 & $5(4.9)$ & $<0.01$ \\
\hline & Disagree & 0 & $2(2)$ & $<0.01$ \\
\hline \multirow{3}{*}{$\begin{array}{l}\text { Smoking (including passive smoking) } \\
\text { may increase the risk of respiratory } \\
\text { disease }\end{array}$} & Agree & $288(96.6)$ & $88(86.3)$ & $<0.01$ \\
\hline & Undecided & $7(2.3)$ & $10(9.8)$ & $<0.01$ \\
\hline & Disagree & $3(1)$ & $4(3.9$ & $<0.01$ \\
\hline \multirow{3}{*}{$\begin{array}{l}\text { Smoking (including passive smoking) } \\
\text { may increase the risk of cardiovascular } \\
\text { disease }\end{array}$} & Agree & $276(92.6)$ & $85(83.3)$ & 0.02 \\
\hline & Undecided & $19(6.4)$ & $15(14.7)$ & 0.02 \\
\hline & Disagree & $3(1)$ & $2(2)$ & 0.02 \\
\hline \multirow{3}{*}{$\begin{array}{l}\text { Smoking may increase the risk of } \\
\text { neonatal death }\end{array}$} & Agree & $211(70.8)$ & $54(52.9)$ & $<0.01$ \\
\hline & Undecided & $74(24.8)$ & $34(33.3)$ & $<0.01$ \\
\hline & Disagree & $13(4.4)$ & $14(13.7)$ & $<0.01$ \\
\hline \multirow{3}{*}{$\begin{array}{l}\text { Maternal smoking is harmful to the } \\
\text { fetus }\end{array}$} & Agree & $255(85.6)$ & $67(65.7)$ & $<0.01$ \\
\hline & Undecided & $38(12.8)$ & $29(28.4)$ & $<0.01$ \\
\hline & Disagree & $5(1.7)$ & $6(5.9)$ & $<0.01$ \\
\hline \multirow{3}{*}{$\begin{array}{l}\text { Smoking in public places including } \\
\text { hospitals and healthcare centres } \\
\text { should not be allowed }\end{array}$} & Agree & $293(98.3)$ & $88(86.3)$ & $<0.01$ \\
\hline & Undecided & $1(0.3)$ & $5(4.9)$ & $<0.01$ \\
\hline & Disagree & $4(1)$ & $9(8.8)$ & $<0.01$ \\
\hline
\end{tabular}

${ }^{a} \chi^{2}$ test. 


\begin{tabular}{|c|c|c|c|c|}
\hline & Response & $\begin{array}{l}\text { Non-smokers } \\
\quad(n=298) \\
(\%)\end{array}$ & $\begin{array}{l}\text { Smokers } \\
(n=102) \\
(\%)\end{array}$ & $P$ value $^{\mathrm{a}}$ \\
\hline \multirow{3}{*}{$\begin{array}{l}\text { Healthcare professionals have to set a } \\
\text { good example to their patients by not } \\
\text { smoking }\end{array}$} & Agree & $290(97.3)$ & 81 (79.4) & $<0.01$ \\
\hline & Undecided & $4(1.3)$ & 14 (13.7) & $<0.01$ \\
\hline & Disagree & $4(1.3)$ & $7(6.9)$ & $<0.01$ \\
\hline \multirow{3}{*}{$\begin{array}{l}\text { Healthcare professionals should } \\
\text { ask patients about their smoking } \\
\text { behaviour }\end{array}$} & Agree & 253 (84.9) & 75 (73.5) & 0.03 \\
\hline & Undecided & 30 (10.1) & 17 (16.7) & 0.03 \\
\hline & Disagree & $15(5)$ & $10(9.8)$ & 0.03 \\
\hline \multirow{3}{*}{$\begin{array}{l}\text { Healthcare professionals should advise } \\
\text { patients to stop smoking }\end{array}$} & Agree & 282 (94.6) & 86 (84.3) & $<0.01$ \\
\hline & Undecided & $9(3)$ & $10(9.8)$ & $<0.01$ \\
\hline & Disagree & $7(2.3)$ & $6(5.9)$ & $<0.01$ \\
\hline \multirow{3}{*}{$\begin{array}{l}\text { Providing advice about smoking } \\
\text { cessation by healthcare professionals } \\
\text { may increase likelihood of patients } \\
\text { quitting smoking }\end{array}$} & Agree & $190(63.8)$ & 55 (53.9) & 0.14 \\
\hline & Undecided & 83 (27.9) & 33 (32.4) & 0.14 \\
\hline & Disagree & $25(8.4)$ & 14 (13.7) & 0.14 \\
\hline \multirow{3}{*}{$\begin{array}{l}\text { Healthcare professionals should advise } \\
\text { their patients to avoid smoking near } \\
\text { children and pregnant women }\end{array}$} & Agree & 293 (98.3) & 97 (95.1) & 0.15 \\
\hline & Undecided & $2(0.7)$ & $3(2.9)$ & 0.15 \\
\hline & Disagree & $3(1)$ & $2(2)$ & 0.15 \\
\hline \multirow{3}{*}{$\begin{array}{l}\text { Healthcare professionals who smoke } \\
\text { are less expected to advise people to } \\
\text { stop smoking }\end{array}$} & Agree & 268 (89.9) & $82(80.4)$ & 0.01 \\
\hline & Undecided & $21(7)$ & $10(9.8)$ & 0.01 \\
\hline & Disagree & $9(3)$ & $10(9.8)$ & 0.01 \\
\hline \multirow{3}{*}{$\begin{array}{l}\text { Healthcare professionals should } \\
\text { receive professional training on } \\
\text { providing smoking cessation advice } \\
\text { and on smoking cessation strategies }\end{array}$} & Agree & $282(94.6)$ & 89 (87.3) & 0.03 \\
\hline & Undecided & $10(3.4)$ & $6(5.9)$ & 0.03 \\
\hline & Disagree & $6(2)$ & $7(6.9)$ & 0.03 \\
\hline
\end{tabular}

${ }^{a} \chi^{2}$ test.

are more aware of the risks of smoking compared to smokers. This is consistent with results reported by Hodgetts et al. (11), in which physicians and nurses who never smoked were more aware of the risks of smoking compared to those who had smoked. As potential antismoking role models, most healthcare professionals reported that they should set a good example to their patients by not smoking. Also, most of them believe that they should advise their patients to stop smoking, although less than two thirds believe that such advice will increase the likelihood of their patients quitting smoking. In addition, most healthcare professionals reported that they should advise their patients about the risk of passive smoking and avoid smoking near children and pregnant women. Compared to smoking healthcare professionals, non-smokers held more positive attitudes toward providing anti-smoking advice and setting a good example to their patients by not smoking (Table 4). These results are consistent with opinions of physicians and nurses about the same questions $(11,13)$. Accordingly, these results suggest that nonsmoking healthcare professionals play a more professional role if they act as role models in smoking cessation programmes. This is because they are more aware of the risks of smoking and hold positive attitudes toward smoking cessation in comparison 
with healthcare professionals who are smokers.

Unfortunately, anti-smoking counselling was the only available intervention for healthcare professionals to help their patients to quit smoking. However, $<15 \%$ of healthcare professionals reported that they feel well prepared to provide anti-smoking advice. This percentage is lower than that reported by Hodgetts et al. (11), who showed that one third of physicians and nurses feel well prepared to counsel patients about smoking cessation. This low percentage can be explained by the fact that only a quarter of healthcare professionals in the current study had ever received professional training on smoking cessation, compared with half of nurses and more than a third of physicians in the study of Hodgetts et al. (6). Most healthcare professionals reported that they need professional training on providing smoking cessation advice and on smoking cessation strategies. However, one possible barrier to the role of healthcare professionals in advising their patients to stop smoking is that smoking-free policies are not properly enforced in their workplaces. Therefore, patients may not accept such anti-smoking advice when they find some of the healthcare professionals smoking.

Collectively, our results highlight the potential of healthcare professionals working at primary healthcare centres as anti-smoking role models. Smoking-free policies are not enforced in public places and non-smokers cannot avoid passive smoking at such places (9), therefore, the government should enforce smoking-free policies and implement a national campaign against smoking. Our results support the involvement of primary healthcare professionals in such campaigns by providing their patients with anti-smoking advice. However, healthcare professionals should receive professional training on smoking cessation strategies to feel well prepared when they advise their patients about smoking. Another possible approach is to establish special smoking cessation clinics at primary healthcare centres that provide anti-smoking services by well-trained healthcare professionals using counselling, medication and other strategies.

This is believed to be the first study to assess smoking rates and attitudes among healthcare professionals at primary healthcare centres. However, the study sample being restricted to Northern Jordan may limit generalization of the findings to the whole country. So, further studies are required to assess smoking behaviour of healthcare professionals in all governorates of Jordan, and to include those who work in hospitals. Time limitation meant that the questionnaires were filled by the respondents themselves and not by interview. This may have led to misunderstanding of some questions, although the investigators encouraged the respondents to ask for any clarification. Another limitation was that we compared smoking rates with those reported from hospitals in 2008 and 2011 $(15,16)$. Since that time, it is unknown whether smoking rates have changed at hospitals. The current study was only interested in cigarette smoking among healthcare professionals, although other kinds of smoking, including waterpipe and smokeless tobacco, may be popular in Jordan. However, our results still provide important information about smoking rates at primary healthcare centres in northern Jordan, which may provide anti-smoking services.

\section{Conclusions}

Smoking was less prevalent among healthcare professionals working at primary healthcare centres irrespective of their profession. Nonsmoking healthcare professionals were more aware of the risks of smoking and held more positive attitudes toward smoking cessation compared to smoking healthcare professionals. Most healthcare professionals did not feel well prepared to advise their patients about smoking cessation; most probably because they did not receive adequate training on smoking cessation strategies. Our results suggest that healthcare professionals working at primary healthcare centres could act as anti-smoking role models after receiving appropriate professional training.

Funding: None.

Competing interests: None declared.

\section{References}

1. Pope CA 3rd, Burnett RT, Turner MC, Cohen A, Krewski D, Jerrett $\mathrm{M}$, et al. Lung cancer and cardiovascular disease mortality associated with ambient air pollution and cigarette smoke: shape of the exposure-response relationships. Environ Health Perspect. 2011 Nov;119(11):1616-21. PMID:21768054

2. WHO Report on the Global Tobacco Epidemic, 2008: the MPOWER package. Geneva: World Health Organization; 2008 (http://www.who.int/tobacco/mpower/2008/en/, accessed 27 September 2016)

3. Jha P. Avoidable global cancer deaths and total deaths from smoking. Nat Rev Cancer. 2009 Sep;9(9):655-64. PMID:19693096
4. Mackay J. The global tobacco epidemic. The next 25 years. Public Health Rep. 1998 Jan-Feb;113(1):14-21. PMID:9475929

5. Li Z, Yao Y, Yu Y, Shi J, Liu Y, Tao Y, et al. Prevalence and associated factors of passive smoking among women in Jilin Province, China: a cross-sectional study. Int J Environ Res Public Health. 201510 30;12(11):13970-80. PMID:26529002

6. Vozoris N, Lougheed MD. Second-hand smoke exposure in Canada: prevalence, risk factors, and association with respiratory and cardiovascular diseases. Can Respir J. 2008 JulAug;15(5):263-9. PMID:18716689

7. Jaghbir M, Shreif S, Ahram M. Pattern of cigarette and waterpipe smoking in the adult population of Jordan. East Mediterr Health J. 201410 12;20(9):529-37. PMID:25343465 
8. Azab M, Khabour OF, Alzoubi KH, Anabtawi MM, Quttina M Khader $\mathrm{Y}$, et al. Exposure of pregnant women to waterpipe and cigarette smoke. Nicotine Tob Res. 2013 Jan;15(1):231-7. PMID:22573726

9. Haddad L, Abu Baker N, El-Shahawy O, Al-Ali N, Shudayfat T. Secondhand smoke exposure among young adults in a developing country - a Jordanian case. Subst Abuse Rehabil. 201304 24;4:45-53. PMID:24648787

10. Smith DR, Leggat PA. An international review of tobacco smoking among medical students. J Postgrad Med. 2007 JanMar;53(1):55-62. PMID:17244976

11. Hodgetts G, Broers T, Godwin M. Smoking behaviour, knowledge and attitudes among Family Medicine physicians and nurses in Bosnia and Herzegovina. BMC Fam Pract. 200406 11;5:12-8. PMID:15193160

12. Sreedharan J, Muttappallymyalil J, Venkatramana M. Nurses attitude and practice in providing tobacco cessation care to patients. J Prev Med Hyg. 2010 Jun;51(2):57-61. PMID:21155406

13. Movsisyan NK, Varduhi P, Arusyak H, Diana P, Armen M, Frances SA. Smoking behavior, attitudes, and cessation counseling among healthcare professionals in Armenia. BMC Public Health. 201211 24;12:1028-35. PMID:23176746

14. Abdullah AS, Stillman FA, Yang L, Luo H, Zhang Z, Samet JM. Tobacco use and smoking cessation practices among physicians in developing countries: a literature review (19872010). Int J Environ Res Public Health. 201312 30;11(1):429-55. PMID:24380976

15. El-Khushman HM, Sharara AM, Al-Laham YM, Hijazi MA. Cigarette smoking among health care workers at King Hussein Medical Center. J Hosp Med. 2008 May;3(3):281-4. PMID:18571808

16. Shishani K, Nawafleh H, Jarrah S, Froelicher ES. Smoking patterns among Jordanian health professionals: a study about the impediments to tobacco control in Jordan. Eur J Cardiovasc Nurs. 2011 Dec;10(4):221-7. PMID:20826114

17. Bartlett JE, Kotrlik JW, Higgins CC. Organizational Research: Determining Appropriate Sample Size in Survey Research. Inf Technol Learn Perform J. 2001 Spring;19(1):43-50 (https:// www.opalco.com/wp-content/uploads/2014/10/ReadingSample-Size1.pdf)

18. Khabour OF, Alzoubi KH, Eissenberg T, Mehrotra P, Azab M, Carroll MV, et al. Waterpipe tobacco and cigarette smoking among university students in Jordan. Int J Tuberc Lung Dis. 2012 Jul;16(7):986-92. PMID:22525279

19. Barnoya J, Glantz SA. Cardiovascular effects of secondhand smoke: nearly as large as smoking. Circulation. 2005 May 24;111(20):2684-98. PMID:15911719 